\title{
Utilization of Crosslinked Starch Nanoparticles as a Carrier for Indomethacin and Acyclovir Drugs
}

Gina S El-Feky², El-Rafie MH ${ }^{1}$, MA El-Sheikh ${ }^{1}$, Mehrez E El-Naggar ${ }^{1 *}$ and Hebeish A $^{1}$

${ }^{1}$ Textile Research Division, National Research Centre, Cairo, Egypt

${ }^{2}$ Department of Pharmaceutical Technology, National Research Centre, Cairo, Egypt

\begin{abstract}
An eco-friendly nanoprecipitation technique was put forward to synthesize native starch nanoparticles loaded with insoluble drugs such as indomethacin (IND) and Acyclovir (ACV). Factors studied to find out the optimum conditions for preparation of different formulations of crosslinked starch nanoparticles (TPP-StNPs) loaded with insoluble drugs. The factors are $20 \mathrm{mg}, 50 \mathrm{mg}$ of drug concentration and $0.5,1 \mathrm{~g}$ of sodium tripolyphosphate (STPP) while the concentration of starch and surfactant were kept constant. World-class facilities as particle size analyzer, poly dispersity index (PDI), zeta potential, TEM, XRD, FT-IR, UV-vis spectroscopy and DSc were used for evaluation of the resultant crosslinked starch nanoparticles loaded with drug. The sustained release of drugs were evaluated using entrapment efficiency and in vitro release. The data obtained confirmed that there is no chemical interaction between drug (IND, ACV) and crosslinked starch nanoparticles. The results indicate that the best formula for IND loaded starch nanoparticles was 0.5 $\mathrm{g}$ STPP and $20 \mathrm{mg}$ IND while the best formula for ACV nanoparticles was at $0.5 \mathrm{~g}$ STPP and $50 \mathrm{mg}$ ACV drug.
\end{abstract}

Keywords: Nanoprecipitation technique; Crosslinked starch nanoparticles; Factorial design; Indomethacin; Acyclovir; Entrapment efficiency; In vitro release

\section{Introduction}

The field of pharmaceutical science has been developing steadily over the years. Pharmaceutical nanoparticles are submicron-sized, colloidal vehicles that carry drugs to the target or release drugs in a controlled way in the body. Controlled drug delivery offers advantages like reduced dosing frequency, better therapeutic control, reduced side effects, and, consequently, better patient compliance. After preparation, nanoparticles are usually dispersed in liquid [1-5].

Such a system can be administered to humans for example by injection, by the oral route, or used in ointments and ocular products. Alternatively, nanoparticles can be dried to a powder, which allows pulmonary delivery or further processing to tablets or capsules. In drug delivery, nanoparticles should readily be biocompatible (not harmful for humans) and biodegradable (deteriorate and expulse in the body conditions). These properties, as well as targeting and controlled release, can be affected by nanoparticle material selection and by surface modification. Materials such as synthetic polymers, proteins or other natural macromolecules are used in the preparation of nanoparticles. To process these materials into nanoparticles, a variety of preparation techniques exist ranging from polymerization of monomers to different polymer deposition methods.

Biodegradable nanoparticles for pharmaceutical use are prepared from a variety of synthetic and natural polymers. Synthetic polymers such as polyacrylates, polycaprolactones, polylactides and its copolymers with polyglycolides. Natural polymers include e.g. albumin, alginate, gelatin, and probably the most studied natural polymer for pharmaceutical nanoparticle applications: chitosan. The polymers used in the current investigation is native starch have been proposed as a carrier for a number of drugs. Properties such as biodegradability, non-toxicity, good biocompatibility, simple production combined with low cost and ready availability makes them suitable for use in biomedical and pharmaceutical formulations.

Topical delivery of drugs to the skin, one of the most readily accessible organs of the body, has been studied for a long time to understand the pathophysiology of skin diseases or for their effective treatment. Skin separates the vital organs from the outside environment and serves as a protective barrier against physical, chemical and microbial attacks. Although topical application of drug offers many advantages, including avoidance of first-pass metabolism, lower fluctuations in plasma drug levels, targeting of the active ingredient for a local effect and good patient compliance, but the barrier nature of skin makes it difficult for most drugs to penetrate into and permeate through it. There has been wide interest in exploring new techniques to enhance drug absorption through the skin during the past decades [6-10].

Presently, transdermal drug delivery is one of the most promising routes of drug administration. Indomethacin (IND) and Acyclovir (ACV) were selected as model drugs. Poorly soluble drugs are a challenging problem in transdermal formulation; generally, transdermal efficacy is closely related to transdermal drug bioavailability [11].

Acyclovir is an antiviral drug. It slows the growth and spread of the herpes virus in the body. It will not cure herpes, but it can lessen the symptoms of the infection. Acyclovir is converted by viral thymidine kinase to Acyclovir monophosphate, which is then converted by host cell kinases to Acyclovir triphosphate (ACV-TP). ACV-TP, in turn, competitively inhibits and inactivates HSV-specified DNA polymerases preventing further viral DNA synthesis without affecting the normal cellular processes.

Indomethacin (IND), $\{2-\{1-[(4-$ chlorophenyl) $\quad$ carbonyl $]-5-$

${ }^{*}$ Corresponding author: Mehrez E El-Naggar, Textile Research Division, National Research Centre, Cairo, Egypt, Tel: 33345732; E-mail: Mehrez_chem@yahoo.com

Received July 14, 2014; Accepted December 16, 2014; Published January 01, 2015

Citation: El-Feky GS, El-Rafie MH, El-Sheikh MA, El-Naggar ME, Hebeish A (2015) Utilization of Crosslinked Starch Nanoparticles as a Carrier for Indomethacin and Acyclovir Drugs. J Nanomed Nanotechnol 6: 254. doi: 10.4172/2157-7439.1000254

Copyright: (c) 2015 El-Feky GS, et al. This is an open-access article distributed under the terms of the Creative Commons Attribution License, which permits unrestricted use, distribution, and reproduction in any medium, provided the original author and source are credited. 
Citation: El-Feky GS, El-Rafie MH, El-Sheikh MA, El-Naggar ME, Hebeish A (2015) Utilization of Crosslinked Starch Nanoparticles as a Carrier for Indomethacin and Acyclovir Drugs. J Nanomed Nanotechnol 6: 254. doi: 10.4172/2157-7439.1000254

methoxy-2-methyl-1H-INDl-3-yl\} acetic acid\}, has been used as a non-steroidal anti-inflammatory drug (NSAIDs) for topical pharmaceutical preparations. On the other hand, Acyclovir (ACV), \{9-[(2-hydroxyethoxy)methyl] guanine $\}$, is a synthetic purine nucleoside analogue derived from guanine considered the safest and most efficacious drug able to act against herpes simplex viruses (HSV1 and HSV-2) [12-18].

The aim of the present study is to prepare a formulation of drug loaded TPP-StNPs using nanoprecipitation technique and to study the effect of two important parameters on the prepared nanoparticles using factorial design. The two parameters include; the concentration of the crosslinking agent (sodium tripolyphosphate; STPP) and the drug concentration (IND and ACV concentration). Other parameters such as starch as polymer and Tween ${ }^{\circ} 80$ as surfactant were kept constant. Thorough evaluation of the obtained TPP-StNPs loaded with drug using different technique such as particle size analyzer, polydispersity index (PDI), zeta potential, Transmission electron microscopy (TEM), entrapment efficiency, in vitro release studies, Fourier transform infrared spectroscopy (FT-IR), X-ray diffraction (XRD) and Differential Scanning Calorimetry (DSC) were performed [19-23].

\section{Materials and Methods}

\section{Materials}

Starch was kindly supplied by Starch and Glucose Company, Egypt. Indomethacin (IND) was obtained as a gift from Misr Co. for Medical Products, Egypt. Acyclovir (ACV) was a kind gift from Memphis Pharmaceutical Co., Egypt. Tween ${ }^{\circledR} 80>99.9 \%$ was obtained from Sigma- Aldrich Chemie GmbH (Germany). Sodium tripolyphosphate (STPP) was purchased from Sigma-Aldrich Chemical Co. Ltd. Phosphate buffer saline (PBS) was prepared using disodium hydrogen orthophosphate. All other chemicals and reagents used were of pharmaceutical grade.

\section{Methods}

Preparation of Indomethacin (IND) and Acyclovir (ACV) loaded TPP-StNPs: IND and ACV nanoparticles were prepared by nanoprecipitation method as follow: $5 \mathrm{~g}$ of native starch was dissolved in $70 \mathrm{ml}$ distilled water containing $1.5 \mathrm{~g} \mathrm{NaOH}$. This solution was kept under high mechanical stirring for $30 \mathrm{~min}$ at $25^{\circ} \mathrm{C}$. $0.4 \mathrm{~g}$ Tween 80 dissolved in $20 \mathrm{ml}$ distilled water containing different amounts of drug, IND or ACV (20 mg and $50 \mathrm{mg}$ ) was slowly added, followed by the addition of $10 \mathrm{ml} \mathrm{H}_{2} \mathrm{O}$ containing different amounts of STPP $(0.5 \mathrm{~g}$ and $1 \mathrm{~g})$ under continuous highly mechanical stirring, keeping in mind that the total volume of the reaction mixture is $100 \mathrm{ml}$. The reaction mixture was left to stand at room temperature for $2 \mathrm{~h}$ to effect crosslinking with constant agitation rate at $25^{\circ} \mathrm{C}$. The resulting drug encapsulated cross-linked starch nanoparticles were subsequently precipitated by $100 \mathrm{ml}$ of absolute ethanol. The resultant powder were purified by means of centrifugation and washing rinsed twice with $80 / 20$ absolute ethanol/water to remove unreacted compounds and finally with absolute ethanol. The resultant nanoparticles were then isolated by means of centrifugation for $1 \mathrm{~h}$ at $4500 \mathrm{rpm}$. At the end, the supernatant was taken for further analysis to determine the loss in the amount of drug and the supernatant was freeze-dried for $12 \mathrm{~h}$ and kept in closed containers for further analysis. The as described freezedried drug loaded cross-linked starch nanoparticles in the solid state can be easily re-dispersed in distilled water by hand agitation before use [24-28].
Experimental design: The formulations were fabricated according to $2^{2}$ full factorial design allowing the simultaneous evaluation of two formulation variables and their interaction. In the factorial design, two factors were evaluated each at two levels of each variable and experiment were performed at all four possible batches; the crosslinking agent concentration (X1) and that of the drug concentration (X2) in the formulations. JMP' (version 7, SAS, USA) was used.

Characterization of drug loaded TPP-StNPs: The mean particle size, size distribution of nanoparticles and zeta potential were determined by dynamic light scattering (DLS) using a Malvern Zetasizer Nano- ZS-ZEN 1600 (Malvern Instruments Co., UK). Particle size distribution of the nanoparticles is monitored using a polydispersity index (PDI). The morphology of drug loaded TPPStNPs was observed by transmission electron microscopy on a JEOL (JEM-1230) Japan with an acceleration voltage of $120 \mathrm{kV}$.

The chemical interactions between TPP-StNPs and IND or ACV drugs were established through FTIR spectrometry. (Maryland, USA). Differential Scanning Calorimetry (DSC) analysis was carried out in order to identify possible interactions between the components [29].

For assessment of calibration curves for IND and ACV, a specific concentration of each of IND and ACV separately in phosphate buffer saline (PBS) at $\mathrm{pH} 5.5$ mixed with ethanol was scanned spectrophotometrically to determine the wave length of maximum absorbance. Calibration curves were assessed from the absorbance values at $\lambda_{\text {max }}$ of a series of IND and ACV solutions containing different concentrations of each of both drugs.

To determine the entrapment efficiency (E.E.\%) of IND or ACV into crosslinked nanoparticles, the amount of free IND and ACV in supernatant were calculated by measuring the absorbance using UV-Vis spectrophotometer at $251 \mathrm{~nm}$ and $264 \mathrm{~nm}$, respectively. The entrapment efficiency was then calculated from the difference between the total free (IND and ACV) and the initial amount of the drugs.

To determine the in vitro release of IND and ACV drugs from the prepared nanoparticles, the drug loaded TPP-StNPs were placed in PBS ( $\mathrm{pH}$ 5.5) at room temperature and samples were taken in particular time intervals and the released amounts were determined using UV-Vis spectrophotometer.

\section{Results and Discussion}

Nanotechnology appears as a very good alternative system to deliver and to protect drugs. The efficacy of many drugs is often limited by their potential to reach the site of therapeutic action. In most cases (conventional dosage forms), only a small amount of administered dose reaches the target site, while the majority of the drug distributes throughout the rest of the body in accordance with its physicochemical and biochemical properties. Therefore, developing a drug delivery system that optimizes the pharmaceutical action of a drug while reducing its toxic side effects in vivo is a challenging task. One approach is the use of colloidal drug carriers that can provide site or targeted drug delivery combined with optimal drug release profiles. The submicron drug delivery system for drug targeting was developed. Polymeric nanoparticles, which possess a better reproducibility and stability profiles than other carrier like microparticles have been proposed as alternative drug carriers that overcome many of these problems. Here, starch was used as a carrier due to its wide pharmaceutical application. The ability of the prepared nanoparticles to control the release of two poorly soluble model drugs; IND and ACV was assessed. 
Citation: El-Feky GS, El-Rafie MH, El-Sheikh MA, El-Naggar ME, Hebeish A (2015) Utilization of Crosslinked Starch Nanoparticles as a Carrier for Indomethacin and Acyclovir Drugs. J Nanomed Nanotechnol 6: 254. doi: 10.4172/2157-7439.1000254

Page 3 of 8

\begin{tabular}{|c|c|c|c|c|c|c|}
\hline \multirow{2}{*}{\multicolumn{3}{|c|}{ Variables }} & \multirow{2}{*}{ Code } & \multicolumn{3}{|c|}{ Levels } \\
\hline & & & & 1 & & 2 \\
\hline \multicolumn{3}{|c|}{ Cross Linking agent } & X1 & $0.5 \mathrm{gm}$ & & $1 \mathrm{gm}$ \\
\hline \multicolumn{3}{|c|}{ Drug } & X2 & $20 \mathrm{mg}$ & & $50 \mathrm{mg}$ \\
\hline & & & \multicolumn{4}{|c|}{ Responses } \\
\hline $\begin{array}{l}\text { Formula } \\
\text { code }\end{array}$ & $\mathrm{x} 1$ & X2 & $\begin{array}{c}\text { Particle } \\
\text { diameter }\end{array}$ & PDI & $\begin{array}{c}\text { Zeta } \\
\text { Potential }\end{array}$ & $\begin{array}{c}\text { Entrapment } \\
\text { efficiency }(\%)^{\mathrm{a}}\end{array}$ \\
\hline F1 & 0.5 & 20 & 32.67 & 0.519 & -29.1 & 63.72 \\
\hline F2 & 0.5 & 50 & 24.36 & 0.537 & -19.5 & 78.98 \\
\hline F3 & 1 & 20 & 68.06 & 0.385 & -7 & 54.05 \\
\hline F4 & 1 & 50 & 141.8 & 0.365 & -5.15 & 43.36 \\
\hline
\end{tabular}

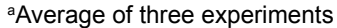

Table 1: Experimental condition, design and responses of $2^{2}$ factorial design preparation of IND nanoparticles.

\begin{tabular}{|c|c|c|c|c|c|c|}
\hline \multirow{2}{*}{\multicolumn{3}{|c|}{ Variables }} & \multirow{2}{*}{ Code } & \multicolumn{3}{|c|}{ Levels } \\
\hline & & & & 1 & \multicolumn{2}{|r|}{2} \\
\hline \multicolumn{3}{|c|}{ Cross Linker } & $\mathrm{X} 1$ & $0.5 \mathrm{gm}$ & & $1 \mathrm{gm}$ \\
\hline \multicolumn{3}{|c|}{ Drug } & $\mathrm{X} 2$ & $20 \mathrm{mg}$ & & $50 \mathrm{mg}$ \\
\hline \multirow[b]{2}{*}{$\begin{array}{l}\text { Formula } \\
\text { code }\end{array}$} & \multirow[b]{2}{*}{$\mathrm{X} 1$} & \multirow[b]{2}{*}{$\mathrm{X} 2$} & \multicolumn{4}{|c|}{ Responses } \\
\hline & & & $\begin{array}{l}\text { Particle } \\
\text { diameter }\end{array}$ & PDI & $\begin{array}{c}\text { Zeta } \\
\text { Potential }\end{array}$ & $\begin{array}{c}\text { Entrapment } \\
\text { efficiency (\%) }\end{array}$ \\
\hline F1 & 0.5 & 20 & 28.21 & 0.269 & -12.2 & 66.07 \\
\hline $\mathrm{F} 2$ & 0.5 & 50 & 15.69 & 0.423 & -35.9 & 74.24 \\
\hline F3 & 1 & 20 & 24.36 & 0.608 & -10.6 & 80.48 \\
\hline $\mathrm{F} 4$ & 1 & 50 & 15.69 & 0.318 & -7.67 & 91.31 \\
\hline
\end{tabular}

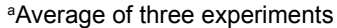

Table 2: Experimental condition, design and responses of $2^{2}$ factorial design preparation of ACV nanoparticles.

\begin{tabular}{|c|c|c|c|c|c|}
\hline Response & Variable & Sum of squares & $\mathbf{d f}^{\mathbf{a}}$ & F value & Prob $>F$ \\
\hline \multirow{3}{*}{$\begin{array}{l}\text { Particle } \\
\text { Diameter }\end{array}$} & $\mathrm{X} 1$ & 5839.2500 & $1^{b}$ & & \\
\hline & $\mathrm{X} 2$ & 1070.2712 & 1 & & \\
\hline & $X 1 * x 2$ & 1070.2712 & 1 & & \\
\hline \multirow{3}{*}{ PDI } & $\mathrm{X} 1$ & 0.0234 & 1 & & \\
\hline & $\mathrm{X} 2$ & 0.0000 & 1 & & \\
\hline & $X 1 * \times 2$ & 0.00361 & 1 & & \\
\hline \multirow{3}{*}{ Zeta Potential } & $\mathrm{X} 1$ & 332.15 & 1 & & \\
\hline & $\mathrm{X} 2$ & 32.77 & 1 & & \\
\hline & $\mathrm{X} 1 * x 2$ & 15.02 & 1 & & \\
\hline \multirow{3}{*}{$\begin{array}{c}\text { Entrapment } \\
\text { efficiency (\%) }\end{array}$} & $\mathrm{X} 1$ & 512.796 & 1 & & \\
\hline & $\mathrm{X} 2$ & 5.220 & 1 & & \\
\hline & $X 1{ }^{*} \times 2$ & 168.350 & 1 & & \\
\hline
\end{tabular}

adegrees of freedom.

bSignificance level based on $1 \mathrm{df} ; \mathrm{p}<0.01$.

Best formulation selected by the program JMP is X1; 0.5 and $\mathrm{X} 2 ; 20$

Desirability; 0.66094

Table 3: Analysis of variance (ANOVA) for a $2^{2}$ Factorial design experiment for evaluation of variables' effect on the IND formulations.

\section{Particle size analyzer and PDI of IND and ACV loaded nanoparticles}

Particle size analysis often used for characterization of formulated nanoparticles, because it facilitates the understanding of the dispersion and aggregation. It has a direct relevance to the stability of the formulation. Larger particles tend to aggregate to a greater extent compared to smaller particles, thereby resulting in sedimentation. PDI is a measure of homogeneity in dispersed systems and ranges from 0 to 1 . Homogeneous dispersion has PDI value close to zero while PDI values greater than 0.5 suggest high heterogeneity [30].

It is seen from Table 1 that the particle size of the IND loaded crosslinked starch is in the range from 24 to $141 \mathrm{~nm}$. The PDI values for all batches are in the range of 0.35 to 0.5 . An increase in the particle size of IND loaded TPP-StNPs with a decrease in PDI was observed with increasing the concentration of STPP. This could be interpreted in terms of increasing the concentration of STPP which provides resistance for mass transfer and in turn diffusion of crosslinked starch-solvent phase into the external phase thereby leading to particle enlargement. The PDI of the prepared formulations reveals that there is a general trend towards uniform particle size distribution. The results also imply outlined that the concentration of IND drug does not influence the particle size distribution of the obtained IND loaded TPP-StNPs.

The average particle size and Polydispersity Index (PDI) of TPPStNPs loaded with ACV drug determined by dynamic light scattering are shown in Table 2.

Table 2 discloses that the particle size for all batches of ACV loaded TPP-StNPs ranged between 15 and $28 \mathrm{~nm}$. The polydispersity index (PDI) for all ACV loaded formulations as shown in Table 3 ranges from the range of 0.269 to 0.423 indicating a narrow and homogenous size distribution of the obtained nanoparticles, except for the ACV nanoparticle formulation (F3) prepared using $1 \mathrm{~g} \mathrm{STPP}$ and $20 \mathrm{mg}$ ACV drug where its PDI slightly exceeds the range (0.608) [4].

\section{Zeta potential of IND and ACV loaded TPP-StNPs}

Surface charge (zeta potential) of IND loaded TPP-StNPs was determined in triplicate by dynamic light scattering (DLS with detection angle of $90^{\circ}$ and $25^{\circ} \mathrm{C}$. Table 1 shows the zeta potential of IND loaded TPP-StNPs containing different concentration of STPP and IND drug.

It was found that the zeta potentials value for all samples of IND loaded TPP-StNPs are slightly negative and in the range of -5 and -29 $\mathrm{mV}$. The average zeta potential value for nanoparticles (F3) prepared at $0.5 \mathrm{~g}$ and $20 \mathrm{mg}$ for STPP and IND, respectively is -29.1 which is sufficiently high to ensure physical stability due to the electrostatic repulsion forces that would avoid aggregation.

Table 2 depicts the zeta potential for all batches of ACV loaded TPP-StNPs.

All of the prepared ACV loaded nanoformulations showed a relatively accepted zeta potential values with F2 showing a zeta potential of $-35 \mathrm{mV}$. This indicates that the prepared drug loaded nanoparticles are expected to assume stability for a long time.

\section{Calibration curves for IND and ACV drugs}

The wavelength of maximum absorbance $(\lambda \max )$ of IND was found to be 264 and for ACV is $251 \mathrm{~nm}$. Calibration curves for IND and ACV were assessed from the absorbance values at $\lambda$ max of each of a series of drugs' solutions containing different concentrations of each of the two drugs. The calibration curve was obtained for IND at 264 $\mathrm{nm}(\mathrm{R} 2=0.9958)$ as shown While the calibration curve for ACV was obtained at $251 \mathrm{~nm}(\mathrm{R} 2=0.9962)$.

\section{Drug entrapment efficency (EE\%) of IND and ACV loaded TPP-StNPs}

The entrapment efficiency is the function of the characteristics of polymer, drug and surfactant, etc. The Entrapment Efficiency was determined by a spectrophotometric method (UV spectrophotometer). Entrapment efficiency of all four grades of IND formulations (F1, 


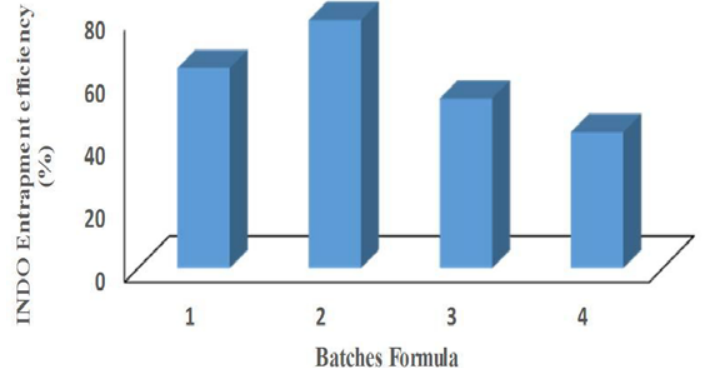

Figure 1: Drug entrapment efficiency of IND loaded crosslinked starch nanoparticles.

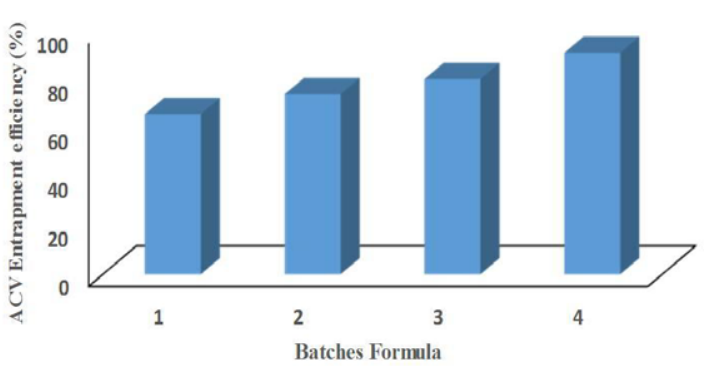

Figure 2: Drug entrapment efficiency of ACV loaded crosslinked starch nanoparticles.

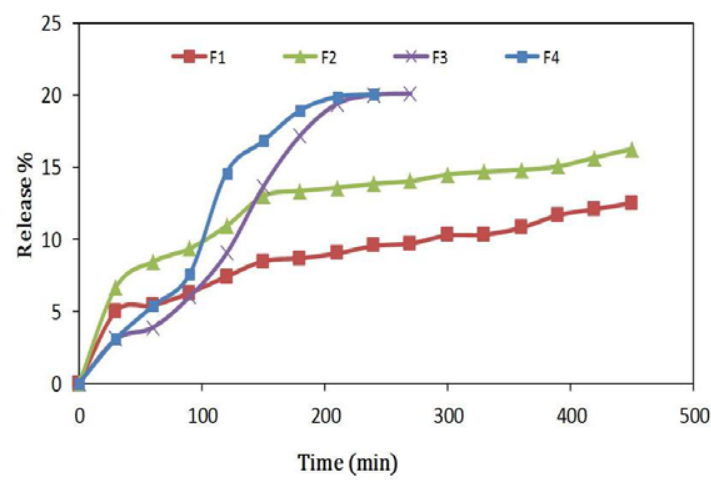

Figure 3: In vitro release of IND drug at absorbance $251 \mathrm{~nm}$ in PBS (pH 5.5).

F2, F3 and F4) is depicted in Figure 1. Obviously, the entrapment efficiency values for these formulations range between 43 and 63\% [7].

Figure 1 implies that the entrapment efficiency was maximum with the smallest particle size of the so obtained IND loaded TPP-StNPs $(24 \mathrm{~nm})$ as well as the higher zeta potential value $(-29.1)$ when the concentration of STPP and IND drug were $1 \mathrm{~g}$ and $50 \mathrm{mg}$, respectively (F2). On the other hand, the entrapment efficiency was minimum with higher drug and STPP concentrations (F4). The particle size had a great influence on the IND entrapment where the smallest particle size of the so obtained nanoparticles have large surface area capable of catching more drug inside and in the outer sphere increasing the efficiency of IND loading for TPP-StNPs.

Entrapment Efficiency (E.E.\%) of ACV loaded TPP-StNPs is deduced from formulations (F1, F2, F3 and F4) under investigation as shown in Figure 2.
It is clear from the data that E.E\% ranges between $66 \%-91 \%$. The data (Figure 2) concluded also that formulation F2 is more favorable when the particle size (15 nm), zeta potential (-35) and PDI (0.4) [16].

\section{In vitro release of IND and ACV from TPP-StNPs}

In vitro release of drug from the prepared nanoparticles an important requirement of successful transdermal therapy is that, a drug carried by a vehicle be able to reach the skin surface at an adequate rate and in sufficient amounts. This makes studying the release profile of drug from nanoparticles crucial in order to predict the behavior of the drug during its transdermal delivery.

In vitro release studies were performed using PBS at $\mathrm{pH} 5.5$ by dialysis bag method using cellulose acetate membrane. Nanoparticles formula equivalent to $20 \mathrm{mg}$ of drug was filled into a dialysis membrane bag and tied at both the ends and placed in a beaker containing $100 \mathrm{~mL}$ of PBS; temperature and speed were maintained at $37^{\circ} \mathrm{C}$ and $50 \mathrm{rpm}$, respectively, using shaking water bath. The drug loaded particles were placed in PBS at room temperature and samples were taken in particular time intervals and UV-vis spectrophotometer measurements were done and the released amounts were determined from a calibration curve

The drug release profile from the prepared nanoparticles can be divided into biphasic pattern: (i) initial burst period, during which the surface drug is dumped into the release medium; here it is taken as $4 \mathrm{~h}$; (ii) slow release period, during which the drug is released at a steady slow rate.

Figure 3 shows the in vitro release of IND drug from the four formulas of the so prepared IND loaded TPP-StNPs containing different concentration of STPP and IND drug when the concentration of starch and surfactant are kept constant. The in-vitro release data of F1, F2 and F3 are displayed in another Figure. The initial values of IND release of F1, F2 and F3 and F4 in 60 min are 4.65\%, 7\%, 3.61\% and $4.5 \%$ respectively.

The responses of these formulations are summarized in Table 3. The variation in the crosslinking agent concentration together with the drug concentration resulted in different drug release rates and profiles [20].

The drug release rate was lower with low concentrations of the crosslinking agent whereas, formulas F3 and F4 with high crosslinking agent concentration showed a burst and uniform release profile i.e. they followed zero order release pattern (F3 and F4 with $\mathrm{R}^{2}$ of 0.9627 and 0.9449 , respectively). It was also noted that the amount of drug released from the four formulations was incomplete during the eight hours period of the experiment. The effect of increasing the drug dose on the release rate was insignificant.

The optimum formulation selected by the $\mathrm{JMP}^{\circ}$ software was composed of $20 \mathrm{mg}$ IND and $0.5 \mathrm{~g}$ crosslinking agent. The calculated desirability factor offered for the formulation was 0.66094. No significant deviations between theoretical and experimental values of tested responses were found [27].

Figure 4 shows the in vitro release of ACV from TPP-StNPs loaded with ACV drug. The release was observed for for formulations containing different amount of STPP and drug (ACV). The ACV drug release exhibits a very slow initial burst that lasted for 60 minute at which $4.76,2.66,4.38$ and $5.22 \%$ of the drug content was released from TPP-StNPs. 
Citation: El-Feky GS, El-Rafie MH, El-Sheikh MA, El-Naggar ME, Hebeish A (2015) Utilization of Crosslinked Starch Nanoparticles as a Carrier for Indomethacin and Acyclovir Drugs. J Nanomed Nanotechnol 6: 254. doi: 10.4172/2157-7439.1000254

Page 5 of 8

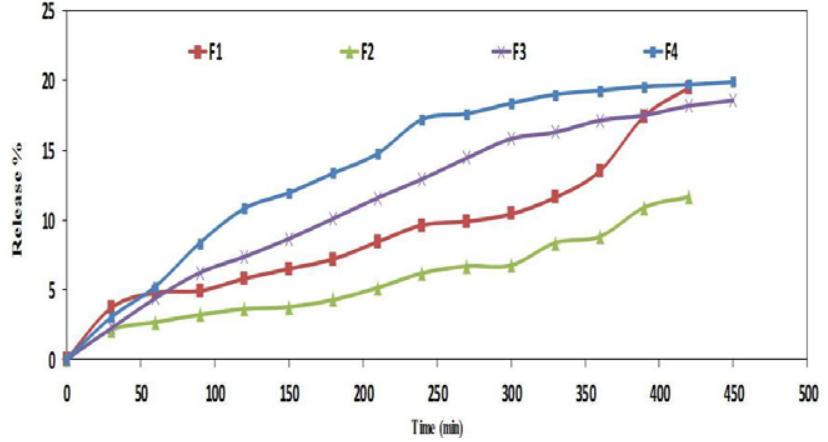

Figure 4: In vitro release of ACV drug at absorbance $264 \mathrm{~nm}$ in PBS (pH 5.5).

\begin{tabular}{|c|c|c|c|c|c|}
\hline Response & Variable & Sum of squares & $d f f^{a}$ & F value & Prob $>F$ \\
\hline \multirow{3}{*}{$\begin{array}{l}\text { Particle } \\
\text { Diameter }\end{array}$} & $\mathrm{X} 1$ & 3.705 & $1^{b}$ & & \\
\hline & $\mathrm{X} 2$ & 112.254 & 1 & & \\
\hline & $X 1 * \times 2$ & 3.706 & 1 & & \\
\hline \multirow{3}{*}{ PDI } & $\mathrm{X} 1$ & 0.0136 & 1 & & \\
\hline & $\mathrm{X} 2$ & 0.00462 & 1 & & \\
\hline & $\mathrm{X} 1 * \times 2$ & 0.04928 & 1 & & \\
\hline \multirow{3}{*}{ Zeta Potential } & $\mathrm{X} 1$ & 222.457 & 1 & & \\
\hline & $\mathrm{X} 2$ & 107.848 & 1 & & \\
\hline & $\mathrm{X} 1 * \times 2$ & 177.289 & 1 & & \\
\hline \multirow{3}{*}{$\begin{array}{c}\text { Entrapment } \\
\text { efficiency (\%) }\end{array}$} & $\mathrm{X} 1$ & 247.747 & 1 & & \\
\hline & $\mathrm{x} 2$ & 90.250 & 1 & & \\
\hline & $\mathrm{X} 1 * \times 2$ & 1.78 & 1 & & \\
\hline
\end{tabular}

adegrees of freedom.

bSignificance level based on $1 \mathrm{df} ; \mathrm{p}<0.01$.

Best formulation selected by the program JMP is $\mathrm{X} 1 ; 0.5 \mathrm{~g}$ and $\mathrm{X} 2 ; 50 \mathrm{mg}$ Desirability; 0.6480

Table 4: Analysis of variance (ANOVA) for a $2^{2}$ Factorial design experiment for evaluation of variables' effect on the ACV formulations.

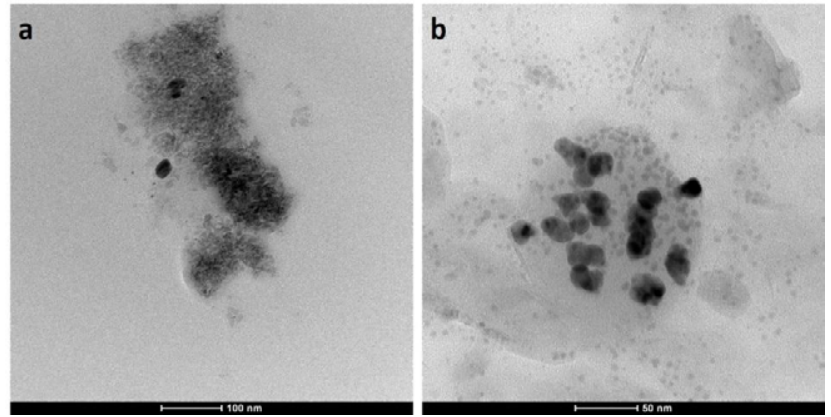

Figure 5: TEM micrograph of IND and ACV loaded crosslinked starch nanoparticles.

A sustained release of the ACV from F1 was observed indicating the encapsulation of ACV within the nanostructures. Since the initial burst effect is very small or was not observed at all tested samples, we can conclude that no initial burst effect was observed for F2 proving that the ACV was not weakly adsorbed onto TPP-StNPs surface.

A significant enhancement in encapsulation of these molecules was observed in the nanoparticles. Nanoparticles were successfully characterized with respect to size, surface morphology and crystallinity of entrapped protein. The release of protein molecules was significantly sustained from nanoparticles. HIP complexation and method of nanoparticles preparation did not affect the structure (secondary and tertiary structure) and activity of the entrapped protein molecules. Colloidal dosage forms have been introduced and widely investigated as drug delivery systems for both hydrophilic and hydrophobic molecules. Nanoparticulate based formulation approach has been verys uccessful for the delivery of small and large molecules [9].

The results of analysis of variance (ANOVA) of the factorial design are presented in Table 4 with a $2^{2}$ design of experiment.

The optimum formulation was selected by the JMP software and was found to be composed of $50 \mathrm{mg}$ drug and $0.5 \mathrm{~g}$ crosslinking agent. The calculated desirability factor offered for the formulation was 0.6480. No significant deviations between theoretical and experimental values of tested responses were found.

Based on all the results reported above, the optimum IND formulation selected by the $\mathrm{JMP}^{\circ}$ software is composed of $20 \mathrm{mg}$ IND and $0.5 \mathrm{~g}$ STPP. The calculated desirability factor offered for the formulation is 0.66094 . However, the optimum ACV formulation selected by the JMP software was found to be composed of $50 \mathrm{mg}$ ACV and $0.5 \mathrm{~g}$ TTP. The calculated desirability factor offered for the formulation was 0.6480 .

\section{TEM of IND and ACV loaded TPP-StNPs}

Considering the results of IND loaded TPP-StNPs pertaining to particle size and entrapment efficiency, batch F1 was chosen for further studies as it has smaller particle size $(32.67 \mathrm{~nm})$ than the other batches with higher entrapment efficiency $(63.72 \%)$. The zeta potential of best formulation has a value of $-29.1 \mathrm{mv}$.

On the other hand, the F2 for ACV loaded TPP-StNPs was chosen as the best formulation since it has the smallest particle size $(15.69 \mathrm{~nm})$, the higher zeta potential value $(-35.9)$ as well as higher entrapment efficiency $(74.24 \%)$ compared with the other formulation.

Figures $5 a$ and $5 b$ shows the TEM micrograph of the selected formulations of IND and ACV loaded TPP-StNPs. As can be seen, the TEM micrographs speak of the formation of spherical nanoparticles with smallest size and smooth surface [1].

\section{XRD of IND and ACV loaded TPP-StNPs}

Mechanical properties of polymers can be altered by the degree of crystallinity. For instance, because of the uniform arrangement of its chains within the lattice structure, a crystalline polymer will degrade more slowly than an amorphous one. However, crystalline polymers are brittle and usually less suited for drug delivery applications. Further, amorphous polymers possess poor mechanical toughness. For that reason, polymers used in drug delivery are usually a mixture of crystalline and amorphous forms, as is the case in current study. The $\mathrm{X}$-ray diffractograms of pure drug IND and promising formulations are shown in Figure 6.

The diffractogram of IND showed characteristic sharp intensity diffraction peaks at $2 \theta$ values of $10.05^{\circ}, 11.51^{\circ}, 12.68^{\circ}, 16.58^{\circ}, 19.52^{\circ}$, $21.84^{\circ}, 23.10^{\circ}, 26.54^{\circ}$ and $29.21^{\circ}$ which reflect the crystalline nature of drug (Figure 6a).

As can be seen in Figure 6b, X-ray diffraction shows two amorphous halos between $10^{\circ}$ and $35^{\circ}(2 \theta)$ as observed for the amorphous polymer. This result suggests a reduced degree of crystallinity of the drug in this formulation. Moreover, the absence of characteristic peaks of IND crystallinity indicates a quite successful 
Citation: El-Feky GS, El-Rafie MH, El-Sheikh MA, El-Naggar ME, Hebeish A (2015) Utilization of Crosslinked Starch Nanoparticles as a Carrier for Indomethacin and Acyclovir Drugs. J Nanomed Nanotechnol 6: 254. doi: 10.4172/2157-7439.1000254

Page 6 of 8
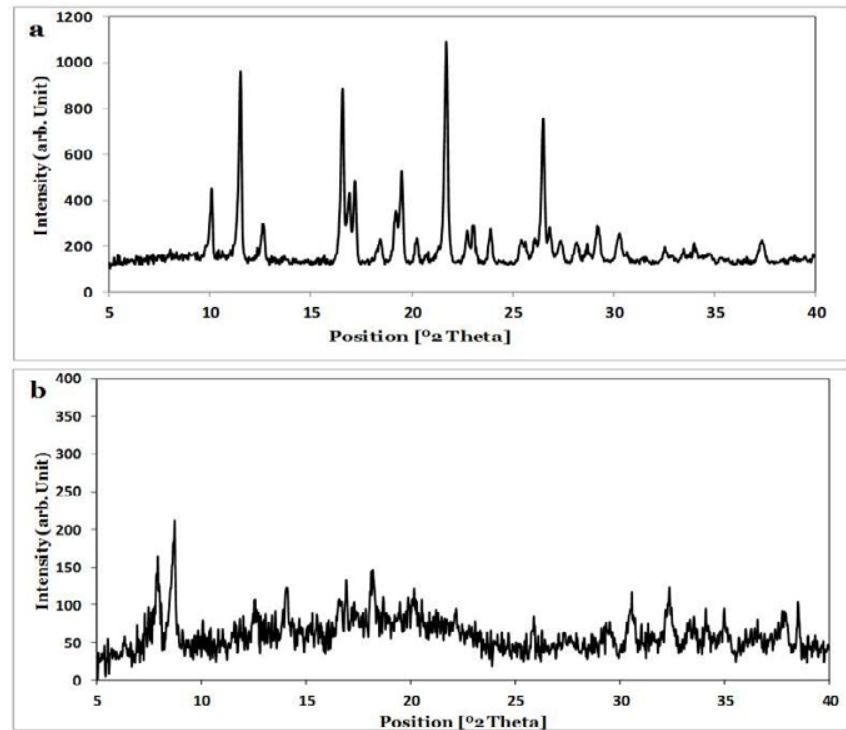

Figure 6: XRD (a) pure IND, (b) crosslinked starch nanoparticles loaded with IND drug.
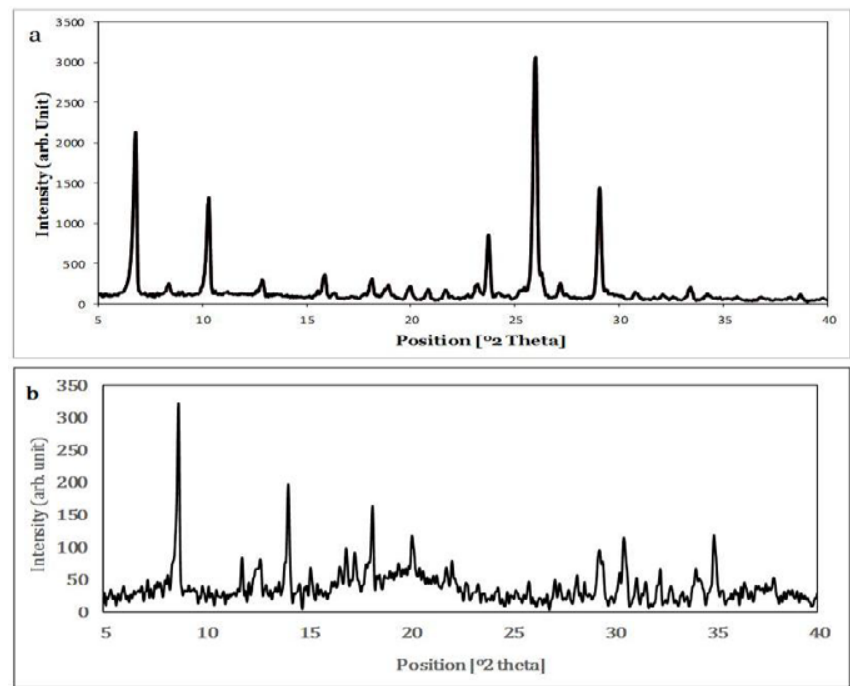

Figure 7: XRD of (a) pure ACV drug, (b) crosslinked starch nanoparticles loaded with ACV drug.

IND encapsulation process, regardless of the amount of TPP-StNPs used.

The X-ray diffractograms of pure drug ACV and promising formulation are shown in Figure 7. The diffractogram of ACV showed characteristic sharp intensity diffraction peaks at $2 \theta$ values of $10.05^{\circ}$, $11.51^{\circ}, 12.68^{\circ}, 16.58^{\circ}, 19.52^{\circ}, 21.84^{\circ}, 23.10^{\circ}, 26.54^{\circ}$ and $29.21^{\circ}$ which reflect the crystalline nature of drug.

The XRD of nanoparticle after incorporation of pure ACV into the starch nanoparticles cross-linked with STPP displays diffraction peaks at respective $2 \theta$ values of pure ACV although their relative intensities were reduced or there was slight shift in their peaks, suggesting reduced degree of crystallinity of drug in this formulation.

\section{FT-IR of IND and ACV loaded TPP-StNPs}

The FTIR spectra of IND and the IND-loaded TPP-StNPs are presented in Figure 8. In the IND spectrum shows characteristic peaks at $3016.12 \mathrm{~cm}^{-1}$ (aromatic C-H stretching), $2917.77 \mathrm{~cm}^{-1}(\mathrm{C}-\mathrm{H}$ stretching vibrations), $1693.19 \mathrm{~cm}^{-1}$ (C = O stretching vibrations), $1690.3 \mathrm{~cm}^{-1}$ is assigned to benzoyl vibration. $1224.92 \mathrm{~cm}^{-1}$ (asymmetric aromatic $\mathrm{O}-\mathrm{C}$ stretching), $1064.51 \mathrm{~cm}^{-1}$ (symmetric aromatic $\mathrm{O}-\mathrm{H}$ stretching).

The FT-IR of IND loaded cross-linked starch nanoparticles show the distinct peaks of pure IND with a slight shift, demonstrating that the drug was incorporated into the particles and there is no possible chemical interaction between cross-linked starch nanoparticle and IND drug.

On the other hand, FT-IR spectra of ACV and ACV loaded TPP-StNPs are shown in Figure 9. ACV exhibits absorption peaks at $3438.45,1630.51,1607.37,1387.53,1306.53,1228.32$ and $1187.89 \mathrm{~cm}$ ${ }^{1}$. Peaks at 3438.45 may be due to $-\mathrm{OH}$ stretching and those at 1630.51 and $1607.37 \mathrm{~cm}^{-1}$ may be assigned to $\mathrm{C}=\mathrm{O}$ stretching. Peak observed

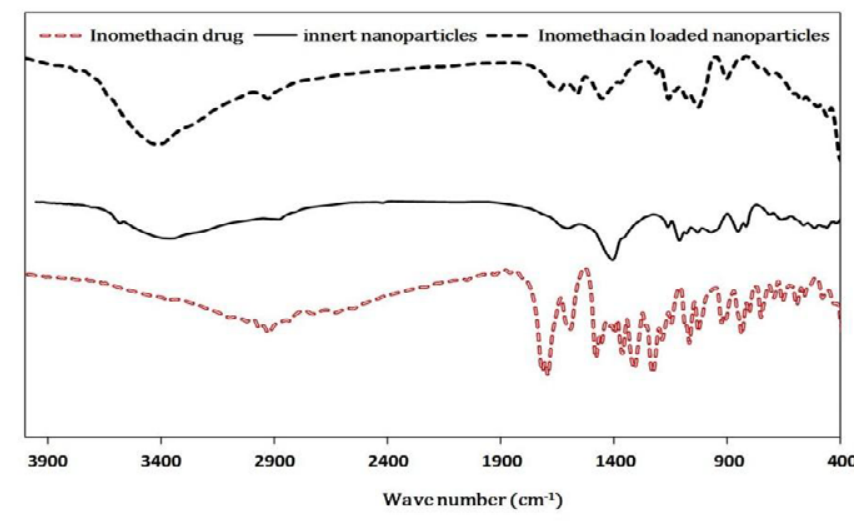

Figure 8: FT-IR of pure IND drug, innert nanoparticles and IND loaded nanoparticles.

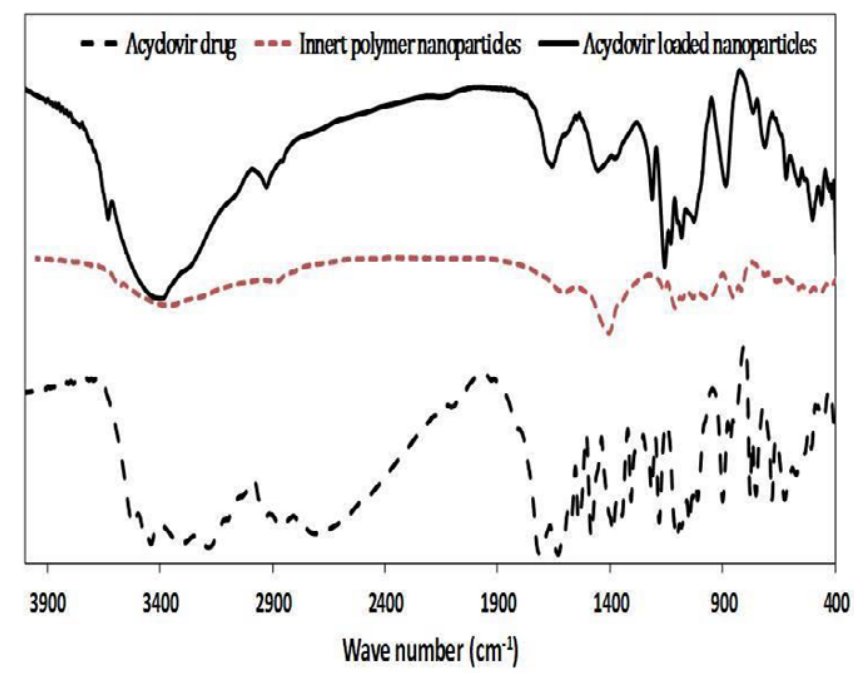

Figure 9: FT-IR of pure ACV drug, innert polymer nanoparticles and ACV loaded nanoparticles. 
Citation: El-Feky GS, El-Rafie MH, El-Sheikh MA, El-Naggar ME, Hebeish A (2015) Utilization of Crosslinked Starch Nanoparticles as a Carrier for Indomethacin and Acyclovir Drugs. J Nanomed Nanotechnol 6: 254. doi: 10.4172/2157-7439.1000254

Page 7 of 8

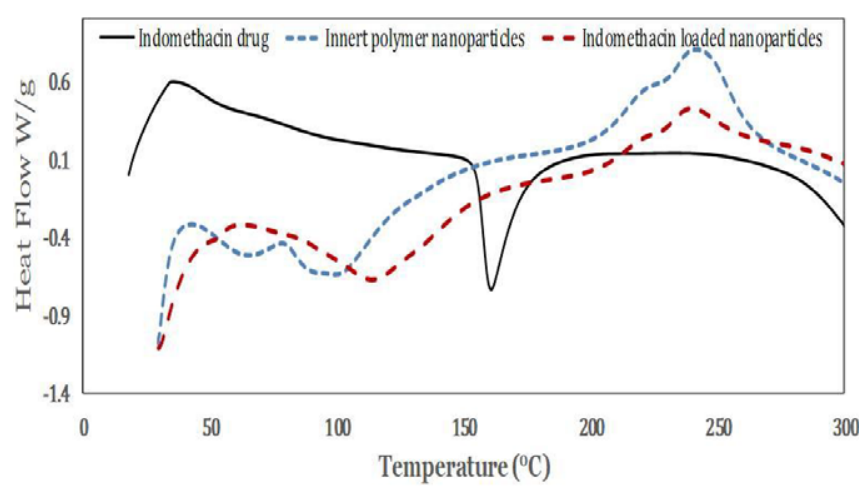

Figure 10: DSC of pure IND drug, innert polymer nanoparticles (crosslinked starch nanoparticles) and IND loaded nanoparticles (IND loaded crosslinked starch nanoparticles.

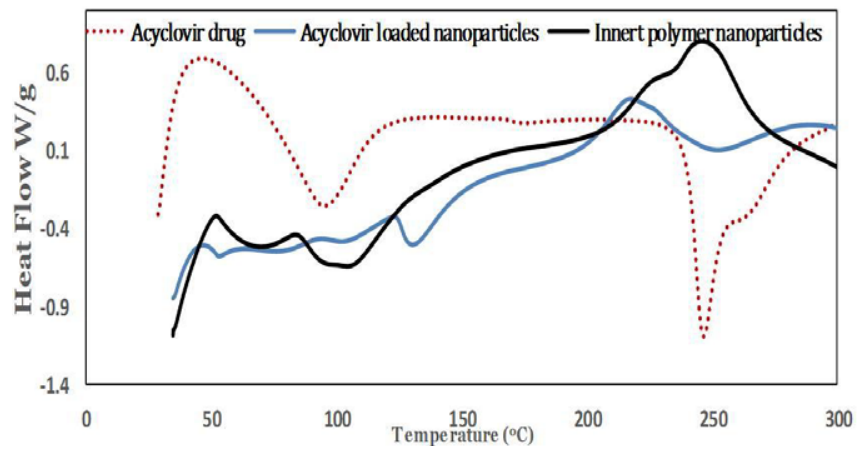

Figure 11: DSC of pure ACV drug, innert polymer nanoparticles (crosslinked starch nanoparticles) and ACV loaded nanoparticles (ACV loaded crosslinked starch nanoparticles.

at $1387.53 \mathrm{~cm}^{-1}$ is due to $\mathrm{C}-\mathrm{N}$ stretching and peaks in the range of 1228.32 to $1187.89 \mathrm{~cm}^{-1}$ may be due to $\mathrm{N}-\mathrm{H}$ stretching [11].

The FTIR of ACV loaded TPP-StNPs corresponds to the superimposition of the spectra of ACV with no significant shift in the major peaks corresponding to ACV. The spectral data indicates no possible interaction between $\mathrm{ACV}$ and cross-linked starch nanoparticles.

\section{DSC of TPP-StNPs loaded with IND and ACV drug}

The thermal behaviour of TPP-StNPs loaded with IND and ACV drugs in comparison with thermograms of pure IND and ACV is illustrated in Figures 10 and 11. The DSC thermogram of pure IND exhibits a sharp endothermic peak at $161.41^{\circ} \mathrm{C}$ corresponding to its melting point, indicating its crystalline nature. TPP-StNPs loaded with IND shows endothermic melting peak at $115.84^{\circ} \mathrm{C}$. This indicates that the drug is present in non-crystalline state in the nanoparticle formulation. Alternatively, this result might be explained in terms of formation of an amorphous form of drug. It is known that transforming the physical state of the drug to amorphous state leads to a high-energy state and high disorder, resulting in enhancing solubility and faster dissolution.

On the other hand, DSC curves obtained for pure drug (ACV) and TPP-StNPs loaded with ACV drug are shown in Figure 11. The DSC thermogram of ACV is characterized by characteristic endothermic peaks at $96.88^{\circ} \mathrm{C}, 176.05^{\circ} \mathrm{C}$ and sharp endothermic peak at $246.53^{\circ} \mathrm{C}$ which are near to its melting point $253^{\circ} \mathrm{C}$. In the DSC curve of TPPStNPs loaded with ACV displays small peaks, which appear in the temperature range of $50-130^{\circ} \mathrm{C}$, and these peaks correspond to the evaporation of water. In addition, the endothermic peaks at $96.88^{\circ} \mathrm{C}$, $176.05^{\circ} \mathrm{C}$ for ACV disappears after ACV is incorporated into TPPStNPs.

Furthermore, no sharp endotherm peak is seen at $246.53^{\circ} \mathrm{C}$. This shows that the crystallinity of the drug reduces significantly in the nanoparticles. The change in endothermic peaks of ACV after loading confirms that the ACV drug is present in the amorphous phase and perhaps homogeneously dispersed in TPP-StNPs.

The modified starch nanoparticles were cross-linked with sodium tripoly phosphate for better stabilization. Morphology of the grafted starch nanoparticles was studied by SEM and AFM. Drug-loading and the controlled release of the drug from the nanoparticles was studied using indomethacin as model drug.

\section{Conclusion}

Polymeric nanoparticles which posess a better reproducibility and stability profile than other carrier like microparticles have been studied as alternative drug carrier. The results obtained indicated that (a) the best formula for IND loaded starch nanoparticles with small spherical size and PDI, high zeta potential, high entrapment efficiency and controlled release was at $0.5 \mathrm{~g}$ STPP and $20 \mathrm{mg}$ IND. On the other hand, the best formula for ACV loaded starch nanoparticles was at $0.5 \mathrm{~g}$ STPP and 50 mg ACV. (b) FT-IR, XRD and DSC indicated that there is no chemical interaction between TPP-StNPs and drug (IND or ACV). The results obtained could be attributed to the dependence of the in vitro release rate of IND and ACV on the viscosity of starch when native starch have higher holding capacity and entrapment efficiency for loading the drugs under investigation. The polyether-polyurethane crosslinked with SNPs nanocomposite film exhibited thermo-responsive electrical conductivity.

\section{References}

1. Desai $D$, Shah $D(2013)$ Implication of nanoparticles for controlled drug delivery system. International Journal of Pharmceutical Sciences and Research 4: 2478-2488.

2. Zhang JF, Sun $X(2004)$ Mechanical properties of poly(lactic acid)/starch composites compatibilized by maleic anhydride. Biomacromolecules 5: 14461451.

3. El-Rafie MH, El-Naggar ME, Ramadan MA, Fouda MMG, Al-Deyab SS, et al. (2011) Environmental synthesis of silver nanoparticles using hydroxypropyl starch and their characterization. Carbohydrate Polymers 86: 630-635.

4. Hebeish A, El-Naggar ME, Fouda MMG, Ramadan MA, Al-Deyab SS, et al (2011) Highly effective antibacterial textiles containing green synthesized silver nanoparticles. Carbohydrate Polymers 86: 936-940.

5. Hebeish A, El-Rafie M, El-Sheikh M, El-Naggar ME (2013) Nanostructura features of silver nanoparticles powder synthesized through concurrent formation of the nanosized particles of both starch and silver. Journal of Nanotechnology.

6. Kreuter J (1994) Nanoparticles, in encyclopedia of pharmaceutical technology Swarbrick and J.C. Boylan, New York: 165-190.

7. Pinto Reis C, Neufeld RJ, Ribeiro AJ, Veiga F (2006) Nanoencapsulation i. Methods for preparation of drug-loaded polymeric nanoparticles. Nanomedicine: Nanotechnology, Biology and Medicine 2: 8-21.

8. Hebeish A, El-Rafie M, EL-Sheikh M, El-Naggar ME (2014) Ultra-fine characteristics of starch nanoparticles prepared using native starch with and without surfactant. Journal of Inorganic and Organometallic Polymers and Materials 24: 515-524

9. Soppimath KS, Aminabhavi TM, Kulkarni AR, Rudzinski WE (2001) Biodegradable polymeric nanoparticles as drug delivery devices. Journal of Controlled Release 70: 1-20. 
Citation: El-Feky GS, El-Rafie MH, El-Sheikh MA, El-Naggar ME, Hebeish A (2015) Utilization of Crosslinked Starch Nanoparticles as a Carrier for Indomethacin and Acyclovir Drugs. J Nanomed Nanotechnol 6: 254. doi: 10.4172/2157-7439.1000254

Page 8 of 8

10. Hans ML, Lowman AM (2002) Biodegradable nanoparticles for drug delivery and targeting. Current Opinion in Solid State and Materials Science 6: 319-327.

11. Kumari A, Yadav SK, Yadav SC (2010) Biodegradable polymeric nanoparticles based drug delivery systems. Colloids and Surfaces B: Biointerfaces 75: 1-18.

12. Langer K, Coester C, Weber C, von Briesen H, Kreuter J (2000) Preparation of avidin-labeled protein nanoparticles as carriers for biotinylated peptide nucleic acid. European Journal of Pharmaceutics and Biopharmaceutics 49: 303-307.

13. Merodio M, Arnedo A, Renedo MJ, Irache JM (2001) Ganciclovir-loaded albumin nanoparticles: Characterization and in vitro release properties. European Journal of Pharmaceutical Sciences 12: 251-259.

14. Zahoor A, Sharma S, Khuller GK (2005) Inhalable alginate nanoparticles as antitubercular drug carriers against experimental tuberculosis. International Journal of Antimicrobial Agents 26: 298-303.

15. Saxena A, Sachin K, Bohidar HB, Verma AK (2005) Effect of molecular weight heterogeneity on drug encapsulation efficiency of gelatin nano-particles. Colloids Surf B Biointerfaces 45: 42-48.

16. Bajpai AK, Choubey J (2006) Design of gelatin nanoparticles as swelling controlled delivery system for chloroquine phosphate. Journal of Materials Science: Materials in Medicine 17: 345-358.

17. Agnihotri SA, Mallikarjuna NN, Aminabhavi TM (2004) Recent advances on chitosan-based micro- and nanoparticles in drug delivery. Journal of Controlled Release 100: 5-28.

18. Teramoto N, Motoyama T, Yosomiya R, Shibata M (2002) Synthesis and properties of thermoplastic propyl-etherified amylose. European Polymer Journal 38: 1365-1369.

19. Teramoto N, Motoyama T, Yosomiya R, Shibata M (2003) Synthesis, thermal properties, and biodegradability of propyl-etherified starch. European Polymer Journal 39: 255-261.
20. Alberta Araújo M, Cunha AM, Mota M (2004) Enzymatic degradation of starchbased thermoplastic compounds used in protheses: Identification of the degradation products in solution. Biomaterials 25: 2687-2693.

21. Hebeish A, El-Rafie M, Rabie A, El-Sheikh M, El-Naggar ME (2014) Ultramicrostructural features of perborate oxidized starch. Journal of Applied Polymer Science 131: 1-9.

22. Hebeish A, El-Rafie MH, El-Sheikh MA, Seleem AA, El-Naggar ME (2014) Antimicrobial wound dressing and anti-inflammatory efficacy of silver nanoparticles. Int J Biol Macromol 65: 509-515.

23. Williams AC (2003) Transdermal and topical drug delivery from theory to clinica practice. Pharmaceutical press, London, UK.

24. Barry BW (2001) Novel mechanisms and devices to enable successfu transdermal drug delivery. European Journal of Pharmaceutical Sciences 14: 101-114.

25. Volpato NM, Nicoli S, Laureri C, Colombo P, Santi P (1998) In vitro acyclovir distribution in human skin layers after transdermal iontophoresis. Journal of Controlled Release 50: 291-296.

26. Bouwstra JA, Honeywell-Nguyen PL (2002) Skin structure and mode of action of vesicles. Advanced Drug Delivery Reviews 54: S41-S55.

27. Prausnitz MR, Langer R (2008) Transdermal drug delivery. Nat Biotech 26 1261-1268.

28. Richards DM, Carmine AA, Brogden RN, Heel RC, Speight TM, et al. (1983) Acyclovir. A review of its pharmacodynamic properties and therapeutic efficacy. Drugs 26: 378-438.

29. De Clercq E (2004) Antiviral drugs in current clinical use. J Clin Virol 30: 115 133.

30. Bhosale U, Kusum DV, Jain N (2011) Formulation and optimization of mucoadhesive nanodrug delivery system of acyclovir. J Young Pharm 3: 275 283. 